\title{
DÜBLIN
}

Technological University Dublin

ARROW@TU Dublin

\section{Creating a Digital SME Community in the Irish Construction Industry}

\author{
Alan V. Hore \\ Technological University Dublin, alan.hore@tudublin.ie \\ Roger West \\ Trinity College, rwest@tcd.ie \\ Alan Redmond \\ Technological University of Dublin, d99101075@mydit.ie
}

Follow this and additional works at: https://arrow.tudublin.ie/beschreccon

Part of the Construction Engineering and Management Commons

\section{Recommended Citation}

Hore, A.V., West, R.P. and Redmond, A., (2009), Creating a Digital SME Community in the Irish Construction Industry, Managing Construction for Tomorrow Conference, Istanbul, Turkey, 30th September - 3rd October 2009, Edited by Dikbas A., Ergen E. And Giritli, H., CRC Press, pp.855-doi:10.21427/mfvt-5w25

This Conference Paper is brought to you for free and open access by the School of Surveying and Construction Management at ARROW@TU Dublin. It has been accepted for inclusion in Conference papers by an authorized administrator of ARROW@TU Dublin. For more information, please contact arrow.admin@tudublin.ie, aisling.coyne@tudublin.ie, gerard.connolly@tudublin.ie.

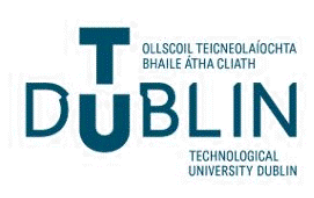




\title{
Creating a Digital SME Community in the Irish Construction Industry
}

\author{
A.V. Hore \\ Dublin Institute of Technology, Dublin, Ireland \\ R.P. West \\ Trinity College, Dublin, Ireland \\ A. Redmond \\ Dublin Institute of Technology, Dublin, Ireland
}

\begin{abstract}
The Construction Industry is a sector where ICT and e-business are used to a lesser extent than in most other sectors. The high concentration of SMEs in the construction industry and the typical nature of the service provided in construction, being an on-site and often highly customised service are generally identified as the reason for the low ICT uptake. The majority of Irish companies in the construction sector are SMEs. It is essential that Irish companies become more effective and efficient with eBusiness technologies in order to compete in the global economy. The Construction IT Alliance in Ireland has identified a project programme that will promote Information and Communications Technologies (ICTs) in the Irish Construction Industry and research SMEs needs to develop a strong eBusiness environment and ultimately create a digital solution that will best suit their needs.
\end{abstract}

\section{INTRODUCTION}

According to the most recent Construction Industry Review and Outlook (2009) prepared by DKM Economic Consultants in Ireland current indicators illustrate how the Irish Construction Industry has been relentless in its re-adjustment, which has come about after several years of unsustainable growth (DKM, 2009). A sharp downward adjustment has been recorded since the height of the Irish Construction Industry boom in 2006. This downward adjustment has made traditionally Irish based companies move to selling products and services internationally. The need for Irish companies to be more effective and efficient with eBusiness technologies in order to compete with their competitors was the main incentive for this project.

The authors will present the results of a recently completed research project, called the Construction IT Alliance eXchange (CITAX) project. In 2006 CITA set about to identify the potential for efficiencies that would lead to savings and faster delivery through the implementation of eBusiness in the construction industry. The industry's cyclical nature and competitive environment has made companies appreciate economic benefits. The potential savings for small to medium-size enterprises (SMEs) in particular, in the construction industry were reported as significant (Hore and West, 2007).

The authors present an overview of selected research in the area of defining the services that seeks to assist SMEs in establishing and promoting their e-
Business and related ICT competencies in the Irish construction industry will be reviewed.

In conclusion this paper sets out a strategy for the newly funded CITA Enterprise Innovation Network (EIN) research project secured by CITA which focuses on the ICT needs of SMEs in the Irish Construction Industry. The increasing practice of using ICT by SMEs to develop and become more efficient will enable them to compete more effectively for international projects. CITAs research in identifying and analysing this particular sector will enable SMEs to better export their services and products.

\section{ICT UP-TAKE IN CONSTRUCTION}

According to an Irish government (DETE, 2004) report Ireland was identified as one of the first countries to recognise the potential and challenges of the Internet, with the establishment of an Information Society Commission in 1998, and publication of the Government's first Action Plan for the Information Society. This plan focused on the development of the telecommunications infrastructure and regulatory environment, developing eBusiness opportunities, delivering public services electronically and generally stimulating widespread society engagement with the Internet. The report acknowledged that Ireland has a very strong ICT producing sector and has the potential and opportunity to become a world leader in the emerging digital sectors. However the performance is less than impressive when it comes to the adoption of ICTs by existing enterprises in the non - 
ICT related sectors of the economy. The report suggest that as eBusiness opens up the Irish economy to international competition Irish enterprises should use ICT as a generator of competitive advantage in the context of the environment they operate in and that companies should have ICT systems that are robust and secure in order to obtain maximum benefit.

It was reported in an e-Business W@tch (2006) report that the construction industry is a sector where ICT and e-business are used to a lesser extent than in most other sectors. The two reasons identified for low ICT uptake are:

- The high concentration of SMEs in the construction industry and

- The typical nature of the service provided in construction, being an on-site and often highly customised service.

The eBusiness W@tch 2006 survey data suggested that large construction enterprises are increasing their focus on ICT issues, such as e-procurement systems, collaborative design systems and collaborative document sharing. However, it also stated that there were a low percentage of firms employing ICT practitioners, as well as a low adoption of enterprise resource planning (ERP) software and advanced eprocurement solutions. The survey also mentioned that construction industry enterprises have little focus on hiring ICT practitioners and ICT training and that the use of eStandards are limited in the construction industry but about in line with the weighted all-sectors average (eBusiness W @ tch, 2006).

Hore and West (2004) suggested "A proposal for re-engineering the procurement of building materials by effective use of ICT". The problems associated with procurement of materials in the Irish Construction industry was witnessed first hand through an observation study. The results of the study illustrate the current traditional paper-based approach to material procurement. The process was shown as enormously inefficient due to the volume of paper, too many people involved and lack of a sufficient ICT investment to automate the paper-based audit trail. The authors proposed a re-engineered solution involving a wireless transmission of Purchase Orders, Delivery Notes and Invoices. For example a signed Proof of Delivery (POD) from the point of activity to the suppliers ICT system, to the contractors ICT system The benefits of this ICT uptake reported by Hore and West included reduced costs; reduced administration; reduced risk from unsigned PODs; improved tracking; prompter payment; improved reporting and increased control (Hore and West, 2004).

The concerns of ICT education of Architecture Engineering and Construction (AEC) professionals were identified by Thomas (2004). Thomas reflected on the relationship between these professionals and how the AEC industry should change to include greater and improved use of ICT. Thomas concluded that the creation of separate professional grouping within the AEC industry is identified as a positive benefit but this fragmentation has hindered integration.

\section{RESPONSE OF THE CONSTRUCTION IT ALLIANCE (CITA) IN IRELAND}

\subsection{Background to CITA}

CITA was established as a research project in Dublin Institute of Technology (DIT) in association with the Waterford Institute of Technology (WIT) in May 2001, with the vision of harnessing the potential of ICT in the Irish Construction Industry. CITA was formally incorporated into a company limited by guarantee with no share capital in November 2005. Membership of CITA is open to all stakeholders in the Irish construction industry who all share the CITA vision and want to participate in fulfilling CITA's objectives.

CITA has identified its objectives as:

- To inform the Irish construction sector of ICT developments

- To establish and disseminate good practice in the use of ICT in the Irish Construction Industry

- To encourage ICT related research collaboration between Irish academia and Irish construction practitioners

- To establish and maintain links with relevant national and international organisations

- To encourage the strategic use of IT by all firms in the Irish Construction Industry

\subsection{CITA Research Activity}

In July 2006 CITA initiated the CITAX project as an industry-led networking pilot project. The CITAX project involved a collaboration of 25 industry partners and a government body. The project aimed to demonstrate that significant measurable economic improvements could be achieved by using readily available ICT tools to radically improve business processes in the Irish Construction Industry. The project was supported by Enterprise Ireland (50\%) and CITA membership (50\%) and was completed in June 2008. The project consisted of five separate but collaborative modules, namely:-

Module 1 - Design

Module 2-Trading

Module 3 - Electronic Tendering

Module 4 - Project Management

Module 5 - Computer Aided Measurement (CAM) 
Each of the modules had clear objectives and by demonstrating these objectives their achievements set out steps for future goals. The general conclusion was that clear economic benefits could be achieved through the pilot projects associated with the modules. For example CITAX Module 3 (Electronic Tendering) team aimed to demonstrate that there were clear economic benefits to be achieved by organisations that replaced the traditional paper-based system with an electronic tendering process. A pilot scheme was undertaken using FTP (File Transfer Protocol) technology and the results showed savings of $11 \%$ for Professional Quantity Surveying firms, which equates to a saving across the industry of $€ 0.74 \mathrm{~m}$ per annum; $10 \%$ for contractors on their tender costs, which equates to an industry saving of $€ 4.8 \mathrm{~m}$ per annum and $11 \%$ for sub-contractors, which equates to an industry saving of $€ 3.75 \mathrm{~m}$ per annum.

The European Commission report Sectoral eBusiness Policies in Support of SMEs (2007) commended the fact that CITAX would use live pilot projects to show real benefits of eBusiness for the industry (European Commission, 2007).

\subsection{Current activities}

Current activities include;

- The Construction Enterprise Innovation Network (EIN) to promote ICT research and innovation in SMEs in the Irish Construction Industry.

- CITA Skillnet which is a new Training Network, funded by Skillnets Ltd. for the training programme 2008/2009. It is a tailor made ICT training programme to suit SME company's needs. CITA Skillnet is also involved in the process of designing and developing a Post Graduate Diploma in Construction Informatics in association with DIT Bolton Street and the University of Maribor in Slovenia.

\subsection{Construction Enterprise Innovation Network}

CITA officially launched their EIN project in February 2009. The project is sponsored by Enterprise Ireland. Initially the objectives of this research is to identify the eBusiness and eTendering software products tools and platforms available or potentially available to meet the business needs of SMEs in the construction industry in Ireland. The next phase will be to provide a development strategy for deploying these tools and platforms and the opportunity for CITA to supply an interactive service to its members. The research will also focus on similar research being undertaken in other countries in order to understand the main directions of technology devel- opment. The knowledge extracted from previous research will be analysed and developed to meet future requirements.

The specific services that the EIN network will provide to its members are as follows:

- An initial one-one ICT consultation IT sanity check, advice on available software packages and backup and data protection policies.

- Access to the virtual EIN

- Receipt of regular CITA EIN bulletins

- An invitation to the CITA EIN intra-disciplinary workshops

- Exclusive access to all research results undertaken by CITA EIN

\section{SMALL TO MEDIUM SIZED ENTERPRISES (SMES)}

\subsection{Meaning of SMEs}

According to Hague and Woodburn (2006) an SME is a business that employ-s up to 250 employees. However, Hague and Woodburn also observed the fact that over $99 \%$ of SMEs employ less than 50 people and that three quarters of them do not have any employees, as they are sole operators.

SMEs operate across most industries from complex electronics to traditional business such as manufacturing. According to the European Union eBusiness W@tch (2006) report, there are approximately 2.4 million construction enterprises in EU25 , of which $97 \%$ are small enterprises with fewer than 20 employees. The industry employs about 14 million people, corresponding to about $7 \%$ of the European work force and $28.5 \%$ of industrial employment.

In the Construction Industry Review and Outlook (2008) prepared by DKM Economic Consultants the authors estimated that in the Irish construction sector close to 100,000 workers or almost $40 \%$ of total persons employed at Q2 2008 worked in companies with less than 5 people. These companies experience the lowest decline in employment over the past year (DKM, 2008). In the Central Statistics Office (CSO) Report (2007), SMEs in the construction sector boom reported that more than half of the 227,400 workforce in the sector at that time were either selfemployed or worked for companies with less then 10 people. However, the research also noted that small enterprises generally make less use of more advanced ICT than larger companies. Just under half of small enterprises engaged in innovation activity in 2004 compared with two thirds of larger enterprises (CSO, 2007). 
5 COMPARABLE INTERNATIONAL RESEARCH

\subsection{RICS (Royal Institution of Chartered Surveyors)}

In 2006 the Building Cost Information Service (BCIS) carried out a survey into current tendering procedures. The construction and building research conference survey was sent to 4000 partner/director members of the RICS Quantity Surveying (QS) and Construction. 298 surveys were completed, representing a response rate of $7.4 \%$. The survey showed the hesitation by the industry to deploy eTendering methods. Only $8 \%$ of tenders were sent out in electronic format while a further $27 \%$ were sent in paper and electronic format. Only $7 \%$ of the documents distributed in electronic format were made available via the web. However, nearly $90 \%$ agreed that eTendering lowered administration costs and nearly three-quarters thought that the ability to tender projects electronically would enhance their company's service (Martin, 2008).

\section{$5.2 e-N V I S I O N$}

In accordance to Tarka (2008) the main contribution to the construction industry is not the development of another powerful platform, but the definition and conceptualisation of new eBusiness scenarios and the development of a data model that will provide the basis of standardisation of the concepts managed in construction processes.

\section{The overall objectives of e-NVISION is to}

- use e-Business platforms to enable SMEs to model and adapt particular business scenarios requested by their customers and suppliers;

- to integrate all their enterprise applications following a service-oriented architecture; and

- to incorporate legal, economical and social services, with the final goal of facilitating their participation in the Future European eBusiness Scenarios.

Four future scenarios were identified by eNVISION based on know-how (knowledge and experience) of SMEs involved in projects and how they would work in the future; e-Tendering, e-Site, e-Procurement and e-Quality (Tarka, 2008).

\subsection{Organisation for Economic Co-operation and Development (OECD)}

The OECD is one of the world's largest and most reliable sources of comparable statistics and economic and social data. Researching on social changes or evolving patterns in such sectors as trade, environment and technology are some of the key services provided by the organisation. In reference to the OECD's published report ICT, eBusiness and SMEs (2004), ICT applications are recognised as having the ability to improve information and knowledge management inside a firm and can reduce transaction cost and increase the speed of transaction for both business-to-business (B2B) and business-toconsumer (B2C). The use of ICT by SMEs is increasingly common in a Eurostat survey on ecommerce. Nine out of ten SMEs were equipped with computers at the end of 2000/early 2001 . However it was noted that across the sector internet penetration is generally higher in larger enterprises (OECD, 2004).

\subsection{CISCO Net Impact Research}

For the last seven years, Cisco's Net Impact Research Series has measured the impact of various ICT on business processes, organisational behaviours and on the operating outcomes of both private and public sector enterprises in the US, Canada, Latin America and the Middle East. In Net Impact Canada (2006) the series shifted its focus to SMEs to gauge the level of investment in ICT. The primary goals were to extend the research beyond the large enterprise to evaluate how ICT is helping SMEs succeed in their unique competitive environment. The work is based on a research model developed by Cisco Systems and Illuminas (formely Momentum Research Group) Illuminas conducted the research in partnership with Cisco Canada and info Canada. Some of the key findings were as follow:

- Canadian SMEs interviewed are taking a "big business" approach to their ICT investments and becoming more sophisticated, mirroring some of the ICT investments made by large enterprises, albeit at a level more realistic for the SMEs.

- Three-quarters of the SMEs interviewed are using networking hardware and software and network security solutions to automate, enhance or improve business processes.

- Approximately 50\% of SMEs interviewed report that their ICT strategy is aligned with business strategy.

- $\quad 75 \%$ improved customer service, increased speed information processing and improved communications with customers.

- Technology is key factor in enabling Canadian small business to achieve greater efficiency and growth.

- $80 \%$ report increased speed in information processing and nearly $75 \%$ report increased availability of information to support decision making processes (Shutter, 2006). 


\subsection{Research Comparison Analysis}

Each of the four examples recognises that ICT is a key factor in enabling SMEs to achieve greater efficiency and growth. However, the full potential of these benefits are over shadowed by the construction industry's failure to structure an eBusiness development that can source through knowledge and experience the evolving pattern needs of SMEs in such sectors of trade, environment and technology. The CITA EIN project will achieve this obligation through research and promoting eBusiness technology in the Irish Construction Industry.

\section{CITA ENTERPRISE INNOVATION NETWORK (EIN)}

\subsection{Background}

CITA was selected as one of the three networks in Ireland for funding by Enterprise Ireland under the new EIN programme. The project commenced in early October 2008 and is funded by Enterprise Ireland for a three year period. The project will promote ICT and its use in the Irish Construction Industry. The project will involve carrying out detailed research into the particular needs of CITA SME members and other potential new members.

\subsection{Focus on SMEs}

It is expected that a clear indication of the eBusiness and eTendering IT needs and opportunities for SMEs in the construction industry will become evident. A research programme will be undertaken to identify and analyse:

1. The eBusiness and eTendering software products and services currently available to construction industry SMEs in Ireland.

2. eBusiness and eTendering software products and services available to construction industry SMEs in other relevant countries, which may not be available in Ireland.

3. Current research programmes in other countries which may have a direct bearing on the IT needs of the Irish Construction Industry.
The information received from this analysis combined with the information emerging from the meeting programmes and technology check of EIN members will chart a course for greater effectiveness and efficiency for SMEs in the construction industry, through the use of ICT.

\subsection{Methodology}

The CITA EIN project will follow a formula that is similar to the successful CITAX project discussed earlier in this paper.

- Project Planning - promoting the message of the potential of ICT to the SME sector in the construction industry

- Services currently available - the research data assembled in the CITAX project would be used to classify the products and services. A product/service database would be compiled.

- Services currently available in relevant countries by contacting suppliers of software products and platforms used by SMEs in relevant countries, data and services of relevant products would be added to the service database.

- Current research programmes - a literature and web-based review will be undertaken of the current research programmes identifying the direct relevance to the use of ICT by SMEs.

- Review of the SME needs - findings from the product/service research will be compared with the outcome of the SMEs discussion meetings and the findings from the technology check programme to screen and prioritise the identified products, services, platforms and research programmes.

- Strategy Development - develop a strategy to assist in the development and implementation of the best products, services, platforms and ideas, derived from earlier modules.

\subsection{Key Performance Indicators}

Table 1 below indicates a metric of performance. The six key performance indicators are measurable and reflect the impact of the work to be carried out. These performance indictors will be addressed and assessed at CITA's general meetings in order to evaluate the progress of the research. 


\begin{tabular}{|l|l|l|l|l|}
\hline \multicolumn{1}{|c|}{ Metric Description } & $\begin{array}{c}\text { Year 1 } \\
\text { Metrics }\end{array}$ & $\begin{array}{c}\text { Year 2 } \\
\text { Metrics }\end{array}$ & $\begin{array}{c}\text { Year 3 } \\
\text { Metrics }\end{array}$ & Total \\
\hline $\begin{array}{l}\text { Number of new SME members joining } \\
\text { CITA. } \\
\text { Measure: Additional new members }\end{array}$ & 40 & 100 & 150 & 290 \\
\hline $\begin{array}{l}\text { SME IT Conference } \\
\text { Attendance to match/exceed the number } \\
\text { of new SME members. } \\
\text { Measure: Number of conferences }\end{array}$ & 1 & 2 & 2 & 5 \\
\hline $\begin{array}{l}\text { Steering group established and meeting on } \\
\text { a regular basis } \\
\text { Measure: Number of meetings }\end{array}$ & 1 & 4 & 4 & 9 \\
\hline $\begin{array}{l}\text { A minimum of 2 working groups } \\
\text { established and meeting regularly to } \\
\text { deliver agreed objectives } \\
\text { Measure: Number of group meetings }\end{array}$ & 6 & 24 & 24 & 54 \\
\hline $\begin{array}{l}\text { Number of companies undertaking } \\
\text { eBusiness }\end{array}$ & 0 & 30 & 100 & 130 \\
\hline $\begin{array}{l}\text { Number of companies tendering } \\
\text { electronically }\end{array}$ & 0 & 40 & 100 & 140 \\
\hline
\end{tabular}

Table 1 Key Performance Indicators

\subsection{Progress to-date}

As part of the research into defining the services that will be provided to the EIN members, a series of interviews have already be undertaken with companies that represent a broad spectrum of activity within the construction industry. This spectrum of companies included; one quantity surveying practice, three suppliers, one engineer and four architects. Most of the companies interviewed have reasonable ICT infrastructure and the majority of the companies have specific software to address particular elements of the construction process for example, traffic model simulation. The main problems identified were lack of adequate disaster recovery planning and high capacity broadband. However the current economic climate has made a number of companies focus on the short term revenue.

To date, in year 1, CITA has attracted 16 SMEs to join the network.

\section{CONCLUSION}

It is widely accepted that ICT is becoming a key element of any organisational infrastructure. Indeed, many like to think that the level of an organisation's reliance on ICT in the twenty-first century is similar to the reliance on electricity in the previous century where it was not expected for an organisation to function without electricity (Alshawi, 2007).

The success and effectiveness of ICT in today's world economies has clearly shaped our environment. ICT has improved our supply chain management process, communication ability and business, and still new innovated solutions are being adapted. However, taking other industries into consideration the construction industry still trails behind being reluctant to shift from traditional techniques.

The SME sector is seen as the main contributor to this reluctance in ICT uptake. It is widely acknowledged that if SMEs increase the practice of using ICT they will develop and become more efficient which will able them to compete more effectively both in their domestic and overseas markets.

The CITA EIN programme anticipates that by developing a strong and proactive EIN it will encourage SMEs to use electronic business. Through detailed research into the particular future business needs of CITA SME members and other potential new members combined with information emerging from meeting programmes and technology checks the effectiveness and efficiency of SMEs in the Irish construction industry will materialise. The aim of CITA's EIN research programme is to address the need to promote ICT in the Irish Construction Industry and research SMEs needs to develop a strong eBusiness environment. This paper has set out a methodology within the CITA's EIN project in which the Irish Construction Industry can create a digital SME community to provide a more effective and efficient service in order to compete against its competitors.

\section{REFERENCES}

- Alshawi, M. (2007), Rethinking in Construction and Engineering, Organisational Readiness, Talyor \& Francis, Oxon.

- Central Statistics Office (2007), The Small Business in Ireland Report 2007, CSO publications.

- Department of Enterprise, Trade and Employment (DETE), 2004, eBusiness Strategy: Optimising usage of ICTs by Irish SMEs and micrenterprises, Irish Government Publications, Dublin.

- DKM Economic Consultants (2009), Construction Industry Indicators: Issue 16, available from http://www.environ.ie

- DKM Economic Consultants (2008), Review of the Construction industry 2007 and Outlook 2008 to 2010

- Enterprise \& Industry Directorate General (2006), e-Business W@tch: ICT and e-Business in the Construction Industry, Sector Report No.7/2006.

- European Commission (2007), Sectoral eBusiness Policies in Support of SMEs, Innovative Approaches, Good Practices and Lessons to be learned, eBSN Report, 43-46.

- Hague, P and Woodburn, S (2006) Small \& Medium Enterprises Equal Big Opportunities, B2B International Ltd

- Hore, A.V and West, R.P, (2007), CITAX, Defining XML Standards for data exchange in the construction industry supply chain, $24^{\text {th }}$ W78 
Conference, Maribor, Slovenia, $26^{\text {th }}-29^{\text {th }}$ June 2007.

- Hore, A.V and West, R.P, 2004, 'A proposal for re-engineering the procurement of building materials by effective use of ICT', Incite 2004 conference, Designing Managing and Supporting Construction Projects Through Innovation \& IT Solutions, Langkawi, Malaysia, 375-380.

- Martin, J. (2008), E-tendering-about time too, Royal Institution of Chartered Surveyors publication

- Organisation for Economic Co-operation \& Development (2004), ICT, E-Business and SMEs, OECD publication.

- Shutter, J. (2006) Net Impact Canada 2006, Small and medium-sized enterprises, 2006 Illuminas Global LLC

- Tarka, M. (2008), European Conference on Product \& Process Modelling: eWork and eBusiness in Architecture, Engineering and Construction, CRC Press, 2008, 691-701.

- Thomas, K (2004), Integration, Isolation and IT Education for an improved Architecture and Construction (AEC) Industry, $3^{\text {rd }}$ International Workshop on Construction Information Technology in Education, 7 September 2004, Istanbul, Turkey. 